\title{
Combination psychotropic medicine use in older adults and risk of hip fracture
}

\section{SUMMARY}

Older people might be embarrassed to talk about falling as they worry this may be judged as a loss of their ability to live independently. Ask older patients, at least yearly, if they ever feel unsteady on their feet or if they have fallen.

Consider whether medicines may be contributing to feelings of unsteadiness or falling. Drugs such as benzodiazepines and selective serotonin reuptake inhibitors, particularly if taken together, are associated with a risk of falling and hip fracture.

Review the patient's treatment regimen to see if there are drugs that are no longer required. Psychotropic drugs should usually be tapered gradually so that adverse effects can be minimised.

Involve a range of health professionals to identify and manage the risk of falls. Help patients stay physically active, independent and socially connected.

\section{Introduction}

In Australia, an estimated $30 \%$ of people aged over 65 years living in the community and $50 \%$ of residents of aged-care facilities fall at least once a year. ${ }^{1,2}$ The resultant harm is significant. In 2018, the estimated number of Australians aged 50 years and over who were hospitalised for a hip fracture was $28,000 .^{3}$

An estimated $5 \%$ of those who sustain a hip fracture die in hospital, and more than $10 \%$ are discharged from hospital to an aged-care facility. More than $50 \%$ experience a persistent mobility-related disability one year after their injury. ${ }^{4}$

Falls typically result from multiple interacting factors. The more factors present, the more likely the person is to fall.' Medicines are a modifiable risk factor. Adverse effects such as drowsiness, dizziness, blurred vision, confusion or postural hypotension may all contribute to falls. ${ }^{5,6}$ The association between psychotropic drugs and the increased risk of hip fracture is well recognised. ${ }^{7,8}$ This is likely to be even greater when psychotropic drugs are used in combination.

\section{Psychotropic drugs and hip fracture}

Australians are among the highest users of antidepressants in the world, with approximately $10 \%$ of the adult population using them each day. ${ }^{9}$ Selective serotonin reuptake inhibitors (SSRIs) are commonly used to treat depression. They are often co-prescribed with other drugs, particularly in older people who frequently take multiple medicines to manage multiple morbidities. ${ }^{5,10}$ A systematic review and meta-analysis found that depressive symptoms were consistently associated with falls in older people."

An Australian matched case-control study using data from the Australian Government Department of Veterans' Affairs (DVA) assessed the risk of hip fracture following starting and ongoing use of SSRIs, either alone, or in combination with other psychotropic drugs. ${ }^{12}$ The study included 8828 veterans with hip fracture and 35,310 matched controls of the same age and gender, and examined their medicine use in the previous six months. The average age of the cohort was 88 years and $63 \%$ were women. ${ }^{12}$

The risk of hip fracture was increased for all five groups of drugs tested (antidepressants, opioids, antiepileptic drugs, benzodiazepines and antipsychotics). The highest risk, more than double, was when SSRIs or opioids were started (see Fig.) and it remained high with ongoing use..$^{12}$ International studies have found similar results with SSRIs and opioids. ${ }^{8,13}$ Co-administration exacerbated the risks even further. ${ }^{12}$

\section{Starting benzodiazepines and SSRIs together}

The highest risk of hip fracture is when a benzodiazepine and an SSRI are started together. There is a fivefold increased risk (odds ratio $(O R)=$ 4.7, 95\% confidence interval (CI) 1.7-13) equating to one extra hip fracture for every 17 patients aged 80 years and over who are treated for a year. ${ }^{12}$ For
Kerrie Westaway

Medical writer

Natalie Blacker

Development coordinator

Russell Shute

General practitioner ${ }^{2}$

Rosemary Allin

Pharmacist $^{3}$

Zain Elgebaly

Educational programs

support lead ${ }^{4}$

\section{Oliver Frank}

Specialist general

practitioner, ${ }^{5}$ and Senior research fellow ${ }^{6}$

\section{Nicole Pratt}

Associate professor, ${ }^{7}$ and Lead of evaluation team'

\section{Elizabeth Roughead}

Professor, ${ }^{7}$ and Director

'Veterans' Medicines Advice and Therapeutics Education Services (Veterans' MATES) program, Adelaide

2 Veterans' MATES Clinical Reference Group, Adelaide

${ }^{3}$ Drug and Therapeutics Information Service (DATIS), SA Health, Adelaide

${ }^{4}$ NPS MedicineWise, Sydney

${ }^{5}$ Oakden Medical Centre,

Adelaide

${ }^{6}$ Discipline of General Practice, University of Adelaide

${ }^{7}$ Quality Use of Medicines and Pharmacy Research Centre, School of Pharmacy and Medical Sciences,

University of South

Australia, Adelaide

\section{Keywords}

antipsychotics,

benzodiazepines deprescribing, opioids, selective serotonin reuptake inhibitors 


\section{Fig. Risk of hip fracture associated with starting psychoactive drugs ${ }^{12}$}

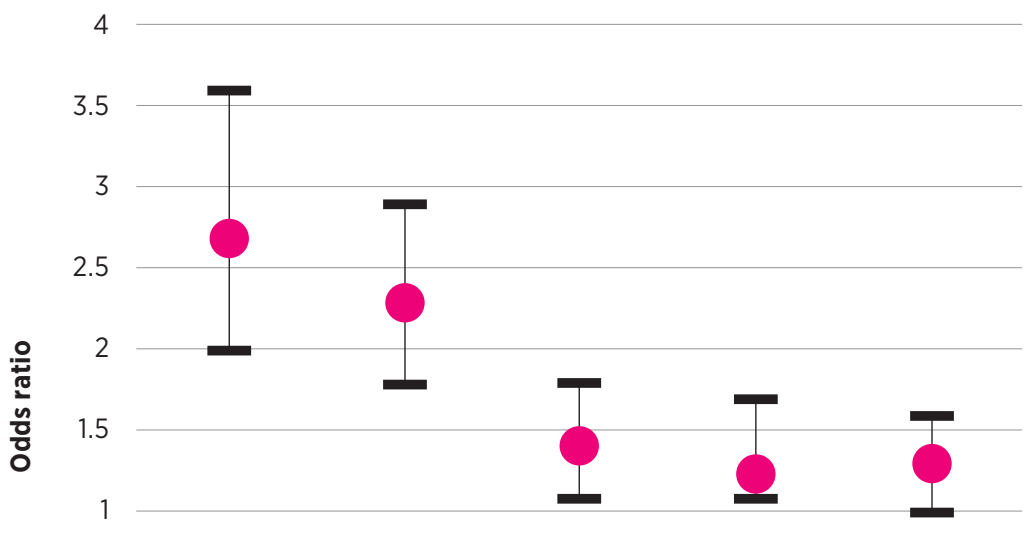

0.5

0
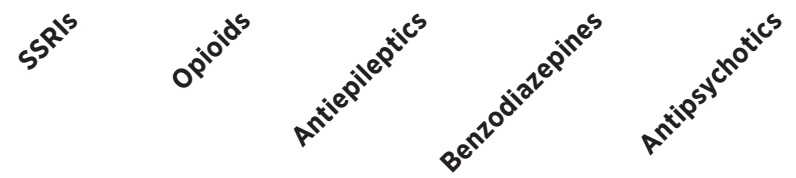

Time interval $=180$ days

95\% confidence interval

SSRI selective serotonin reuptake inhibitor an SSRI increases the risk of hip fracture, with one extra hip fracture for every 29 patients aged 80 years and over who are treated for a year. ${ }^{12}$ There is a need to assess the risk of falls when considering this combination. It may be possible to taper the SSRI in patients who are well, or use an alternative analgesic in older patients who are unsteady on their feet.

\section{Adding antipsychotics to SSRIS}

Starting antipsychotic drugs in patients aged 80 years and over who are already using SSRIs results in one extra hip fracture for every 49 patients treated for a year. ${ }^{12}$ Antipsychotics and antidepressants are commonly prescribed for elderly people with dementia. ${ }^{17}$ However, there is a lack of evidence to show that antidepressants are beneficial in dementia. ${ }^{18,19}$ Antipsychotic use in elderly people is associated with adverse effects linked to falling including orthostatic hypotension, confusion and anticholinergic effects. ${ }^{18,19}$

\section{Strategies to reduce the risk of falls}

There is a range of interventions that can reduce the risk of falls. A multidisciplinary approach may be helpful.

\section{Review the regimen}

Reviewing and modifying older people's medicines to align with their preferences, expectations, treatment goals and level of function is good practice. ${ }^{20}$ Gradual withdrawal of psychotropic drugs can reduce falls. 'When considering which drugs to taper or cease, prioritise them based on their risk and the patient's needs, as well as the ease of dose reduction or cessation, and the availability of safer alternatives. It may be necessary to consult with other prescribers and discuss the options and potential outcomes with the patient. ${ }^{20}$ If deprescribing, stop one drug at a time and wean doses slowly over weeks or months while closely monitoring the patient for benefits or adverse effects. ${ }^{20}$ Stopping too quickly can cause withdrawal syndromes.

Avoid starting an antidepressant for mild to moderate depression. Psychological management alone is appropriate first-line treatment. ${ }^{21}$ For older patients with full resolution of symptoms, consider tapering and ceasing SSRIs. (To find out how to taper and cease an antidepressant, go to: www.veteransmates.net.au/topic-49-therapeutic-brief or www.nps.org.au/australian-prescriber/articles/ switching-and-stopping-antidepressants.)

For older patients taking an opioid for chronic pain, consider a multidisciplinary approach to help them understand why pain can persist even after an injury has healed and how active selfmanagement strategies can help them overcome their 
pain. ${ }^{22}$ Review the use of opioids and, where possible, slowly taper and cease or substitute with a non-opioid analgesic as the patient's ability to regain control and self-manage increases. (To find out how to taper and cease an opioid, go to: www.veteransmates.net.au/ topic-48-therapeutic-brief.)

In dementia, behavioural and psychological symptoms often fluctuate over time, and occur episodically, most commonly as a result of unmet physical or psychological needs combined with impairment of brain function, and lowered stress thresholds due to the disease process. ${ }^{23}$ If an antipsychotic is prescribed for behavioural and psychological symptoms of dementia, limit the dose and duration and also consider the timing of the dose. When possible use non-pharmacological interventions. ${ }^{23}$ (To find out how to taper and cease an antipsychotic, go to: www.veteransmates.net.au/ topic-44-therapeutic-brief.)

Avoid starting benzodiazepines in older patients. If a benzodiazepine is absolutely necessary, use for a short time only, at a low dose and monitor the patient closely. ${ }^{24}$ (For information on how to manage benzodiazepine dependence, and how to taper and cease, go to: www.nps.org.au/news/managingbenzodiazepine-dependence-in-primary-care.)

\section{Discuss risk factors}

Encourage patients to work with a range of health professionals to help them stay active and socially connected. Patients at high risk of falling include those who are visually impaired, have cognitive impairment, advanced diabetes or a neurological disease. ${ }^{1,25}$ Research suggests that multifactorial interventions that include individual assessment, group or home-based exercise programs, and home safety interventions are effective in helping to reduce falls.'

Explain to patients that some medicines can cause adverse effects that might increase their risk of falling. Encourage them to report any dizziness, drowsiness, confusion, or blurred vision. Ask them if they are willing to discuss possible changes to their treatment.

At least once a year and after changes to the treatment regimen, ask older patients if they ever feel unsteady on their feet or if they have fallen. Previous falls increase the risk of subsequent falls. ${ }^{25}$ Reassure patients that many things can be done to help prevent falls and to help them stay steady on their feet. A quick and simple falls-risk screen can identify patients who might be at risk of falling. ${ }^{25}$ This can be added to the template for a GP Management Plan and for health assessments in patients aged over 75 years.
Being involved in group or home-based exercise classes that focus on improving balance and building strength can reduce the risk of falls. It can also help to prevent injuries resulting from a fall.

In Australia, one in four men and two in five women aged 50 years and over sustain a minimal trauma fracture, most commonly because of osteoporosis or osteopenia. ${ }^{26}$ Identify patients, without a history of a previous fracture, who are at high risk of poor bone health and refer them for a bone mineral density scan. There is a Medicare subsidy for bone mineral densitometry for people over 70 years who have not had a bone mineral density scan before and for younger people with specific risk factors for osteoporosis. ${ }^{27}$

\section{Allied health interventions}

Interventions by an occupational therapist to improve home safety can be effective particularly if the patient is at high risk of falling. (To find an occupational therapist, go to: www.otaus.com.au/ find-an-occupational-therapist.)

An assessment of foot pain by a podiatrist and advice about appropriate footwear, ankle and foot exercises, customised insoles and falls prevention strategies can help to reduce the risk of falling. 1,25 DVA funds podiatry services for eligible DVA patients. (To find a podiatrist, go to: www.podiatry.org.au/ find-a-podiatrist.)

Encourage patients to have their eyesight checked every two years or more often if needed. ${ }^{23}$ Remind patients that eye drops or eye ointment can cause blurred vision which can increase their risk of falling.

\section{Conclusion}

Psychotropic drugs increase the risk of falls. SSRIs, used alone or concurrently with benzodiazepines, opioids or antipsychotic drugs, significantly increase the risk of hip fracture and in many elderly patients they may pose an unacceptable risk. The degree to which the risk is increased following concurrent use of these drugs might not be well recognised. Asking patients about whether they have previously fallen and reviewing their medicines can help to reduce their risk. $<$

\section{Conflict of interest: none declared}

Acknowledgement: This article is adapted and reproduced from the Veterans' MATES Therapeutic Brief, Medicines: the hidden contributor to falls and hip fracture. The Australian Government Department of Veterans' Affairs Veterans' MATES Program is provided
SELF-TEST QUESTIONS

True or false?

1. Opioids increase the risk of hip fractures.

2. During the first few weeks of therapy with a selective serotonin reuptake inhibitor a benzodiazepine can reduce the risk of falls.

Answers on page 113 
by the Quality Use of Medicines and Pharmacy Research Centre, Sansom Institute, University of South Australia, in association with Discipline of General Practice, University of Adelaide; Discipline of Public Health, University of
Adelaide: NPS MedicineWise: Australian Medicines Handbook; and Drug and Therapeutics Information Service. Veterans' MATES Program materials are available at: www.veteransmates.net.au.

\section{REFERENCES}

1. Gillespie LD, Robertson MC, Gillespie WJ, Sherrington C, Gates S, Clemson LM, et al. Interventions for preventing falls in older people living in the community. Cochrane Database Syst Rev 2012:CD007146. https://doi.org/ 10.1002/14651858.CD007146.pub3

2. Australian Commission on Safety and Quality in Health Care. Preventing falls and harms from falls in older people: best practice guidelines for Australian residential aged care facilities. Sydney: ACSQHC; 2009. https://www.safetyandquality.gov.au/publications/ preventing-falls-and-harm-from-falls-in-older-people-bestpractice-guidelines-for-australian-residential-aged-carefacilities-2009 [cited 2019 May 1]

3. Watts JW, Abimanyi-Ochom J, Sanders KM. Osteoporosis costing all Australians: a new burden of disease analysis 2012 to 2022. Sydney: Osteoporosis Australia; 2013. https://www.osteoporosis.org.au/research-position-papers [cited 2019 May 1]

4. ANZHFR bi-national annual report for hip fracture care 2017. Australian and New Zealand Hip Fracture Registry; 2017. https://anzhfr.org/2017-annual-report [cited 2019 May 1]

5. Leach M, Pratt N, Roughead E. Medicine use among older Australians before and after hip fracture. J Pharm Pract Res 2013;43:265-8. https://doi.org/ 10.1002/j.2055-2335.2013.tb00271.x

6. Takkouche B, Montes-Martínez A, Gill SS, Etminan M. Psychotropic medicines and the risk of fracture. Drug Saf 2007;30:171-84. https://doi.org/10.2165/ 00002018-200730020-00006

7. Cumming RG, Le Couteur DG. Benzodiazepines and risk of hip fractures in older people: a review of the evidence. CNS Drugs 2003;17:825-37. https://doi.org/10.2165/ 00023210-200317110-00004

8. Wu Q, Bencaz AF, Hentz JG, Crowell MD. Selective serotonin reuptake inhibitor treatment and risk of fractures: a metaanalysis of cohort and case-control studies. Osteoporos Int 2012;23:365-75. https://doi.org/10.1007/s00198-011-1778-8

9. Davey CG, Chanen AM. The unfulfilled promise of the antidepressant medications. Med J Aust 2016;204:348-50. https://doi.org/10.5694/mja16.00194

10. Caughey GE, Roughead EE, Shakib S, McDermott RA, Vitry Al, Gilbert AL. Comorbidity of chronic disease and potential treatment conflicts in older people dispensed antidepressants. Age Ageing 2010;39:488-94. https://doi.org/10.1093/ageing/afq055

11. Kvelde T, McVeigh C, Toson B, Greenaway M, Lord SR, Delbaere K, et al. Depressive symptomatology as a risk factor for falls in older people: systematic review and metaanalysis. J Am Geriatr Soc 2013;61:694-706. https://doi.org/ 10.1111/jgs.12209

12. Leach MJ, Pratt NL, Roughead EE. Risk of hip fracture in older people using selective serotonin reuptake inhibitors and other psychoactive medicines concurrently: a matched case-control study in Australia. Drugs Real World Outcomes 2017:4:87-96. https://doi.org/10.1007/s40801-017-0107-8

13. Kuschel BM, Laflamme L, Möller J. The risk of fall injury in relation to commonly prescribed medications among older people--a Swedish case-control study. Eur J Public Health 2015;25:527-32. https://doi.org/10.1093/eurpub/cku120

14. Furukawa TA, Streiner DL, Young LT, Kinoshita Y. Antidepressant plus benzodiazepine for major depression. Cochrane Database Syst Rev 2001:CD001026. https://doi.org/10.1002/14651858.CD001026

15. Pfeiffer PN, Ganoczy D, Zivin K, Valenstein M. Benzodiazepines and adequacy of initial antidepressant treatment for depression. J Clin Psychopharmacol 2011;31:360-4. https://doi.org/10.1097/ JCP.0b013e318217b4c4
16. Henderson JV, Harrison CM, Britt HC, Bayram CF, Miller GC Prevalence, causes, severity, impact, and management of chronic pain in Australian general practice patients. Pain Med 2013;14:1346-61. https://doi.org/10.1111/pme.12195

17. Moyle W, El Saifi N, Draper B, Jones C, Beattie E, Shum D, et al. Pharmacotherapy of persons with dementia in longterm care in Australia: a descriptive audit of central nervous system medications. Curr Drug Saf 2017;12:95-102. https://doi.org/10.2174/1574886312666170209113203

18. Farina N, Morrell L, Banerjee S. What is the therapeutic value of antidepressants in dementia? A narrative review. Int J Geriatr Psychiatry 2017;32:32-49. https://doi.org/ 10.1002/gps.4566

19. Orgeta V, Tabet N, Nilforooshan R, Howard R. Efficacy of antidepressants for depression in Alzheimer's disease: systematic review and meta-analysis. J Alzheimers Dis 2017;58:725-33. https://doi.org/10.3233/JAD-161247

20. Le Couteur D, Banks E, Gnjidic D, McLachlan A. Deprescribing. Aust Prescr 2011;34:182-5. https://doi.org/ 10.18773/austprescr.2011.095

21. Malhi GS, Outhred T, Hamilton A, Boyce PM, Bryant R, Fitzgerald PB, et al. Royal Australian and New Zealand College of Psychiatrists clinical practice guidelines for mood disorders: major depression summary. Med J Aust 2018;208:175-80. https://doi.org/10.5694/mja17.00659

22. Royal Australasian College of Physicians. Prescription opioid policy: improving mangement of chronic non-malignant pain and prevention of problems associated with prescription opioid use. Sydney: RACP; 2009. https://www.ranzcp.org/ files/resources/college_statements/practice_guidelines/ chronic-non-malignant-pain-2009.aspx [cited 2019 May 1]

23. Burns K, Jayasinha R, Brodaty H. A clinican's field guide to good practice: managing behavioural and pyschological symptoms of dementia. Sydney: Dementia Collaboratve Research Centres - Assessment and Better Care; 2014. http://www.dementiaresearch.org.au/index.php?option= com dcrc\&view $=$ dcrc\&layout $=$ project\&ltemid=112\&research topic $=0$ \&researcher $=77 \&$ research_type $=0$ \&year $=0$ \& population $=0 \&$ centre $=1 \&$ keywords $=\&$ searchtype $=E X A C T \&$ recruiting location id=0\&pid=260\&search=true [cited 2019 May 1]

24. Prescribing drugs of dependence in general practice, Part B: benzodiazepines. Melbourne: The Royal Australian College of General Practitioners; 2015. www.racgp.org.au/clinicalresources/clinical-guidelines/key-racgp-guidelines/viewall-racgp-guidelines/prescribing-drugs-of-dependence/ prescribing-drugs-of-dependence-part-b [cited 2019 May 1]

25. Australian Commission on Safety and Quality in Healthcare. Preventing falls and harms from falls in older people. Best practice guidelines for Australian community care. Sydney: ACSQH; 2009. [PDF] https://www.safetyandquality.gov.au/ wp-content/uploads/2012/01/Guidelines-RACF.pdf [cited 2019 May 1]

26. Australian Insitute of Health and Welfare. Estimating the prevalence of osteoporosis in Australia. Canberra: AlHW; 2014. www.aihw.gov.au/reports/arthritis-othermusculoskeletal-conditions/estimating-the-prevalence-ofosteoporosis-in-austr/contents/table-of-contents [cited 2019 May 1]

27. Australian Government Department of Health. Medicare Benefits Schedule - Item 12306. Category 2 diagnostic procedures and investigations. Bone densitometry. www9.health.gov.au/mbs/fullDisplay. cfm?type=item\&qt=ItemID\&q=12306 [cited 2019 May 1] 